\title{
A NOÇÃO DE ACONTECIMENTO À LUZ DA ANÁLISE DO DISCURSO, DA SEMÂNTICA DO ACONTECIMENTO E DA SEMIÓTICA TENSIVA
}

\author{
The Notion of Event In the Light of La Noción de Acontecimiento a la Luz del \\ Discourse Analysis, Semantics of the Event Análisis de Discurso, la Semántica del \\ and Tensive Semiotics Acontecimiento y la Semiótica Tensiva
}

\author{
Conrado Moreira Mendes* \\ Pontifícia Universidade Católica de Minas Gerais \\ Faculdade de Comunicação e Artes - Departamento de Comunicação Social \\ Belo Horizonte, MG, Brasil \\ Jocyare Souza** \\ Universidade Vale do Rio Verde \\ Três Corações, MG, Brasil \\ Sueli Maria Ramos da Silva*** \\ Universidade Federal do Mato Grosso do Sul \\ Centro de Ciências Humanas e Sociais - Departamento de Letras \\ Campo Grande, MS, Brasil
}

\begin{abstract}
Resumo: No âmbito dos estudos textuais/discursivos, na década de 1980, foi introduzido o conceito de acontecimento pela análise do discurso (AD) pêcheutiana. A partir dos anos 2000, outras perspectivas teóricas, como a semântica do acontecimento, apropriando-se à sua maneira do referido conceito da $\mathrm{AD}$, correlacionam a enunciação como um acontecimento de natureza histórico-social com a língua (o sistema). Uma terceira corrente de estudos discursivos, a semiótica da Escola de Paris, especificamente em sua vertente tensiva, também desenvolve, a seu modo, outra noção de acontecimento: algo da ordem do inesperado e do impactante. Assim, este artigo procura reunir os pontos em comum acerca dos conceitos de acontecimento a partir das referidas teorias, mas, sobretudo, objetiva salientar suas diferenças conceituais e epistemológicas.
\end{abstract}

Palavras-chave: Acontecimento. Análise do discurso. Semântica do acontecimento. Semiótica tensiva.

Abstract: Within the textual/discursive studies in the 1980s, the concept of event was introduced in discourse analysis by Pêcheux. From the 2000s, other theoretical perspectives, such as the semantics of the event, which appropriates the $\mathrm{AD}$ definition in this own way, relates the enunciation as an event of historical-social nature to language (the system). A third line of discourse studies is the French semiotics, specifically its tensive semiotics, also develops another notion of event its own way: something unexpected

\footnotetext{
* Doutor em Semiótica e Linguística Geral Pela USP. ORCID: https://orcid.org/0000-0002-3721-8578. Email: conradomendes@yahoo.com.br.

** Pós-doutora em Linguística pela Unicamp. ORCID: https://orcid.org/0000-0003-2215-0774. E-mail: prof.jocyare.souza@unincor.edu.br.

*** Doutora em Semiótica e Linguística Geral Pela USP. ORCID: https://orcid.org/0000-0002-2631-066X. E-mail: profa.dra.sueliramos@gmail.com.
} 
and impactful. Thereunto, this paper seeks to bring together the commonalities about the concept of event from those theories, but it mainly pursues emphasize their conceptual and epistemological differences.

Keywords: Event. Discourse analysis. Semantics of the event. Tensive semiotics.

Resumen: En el ámbito de los estudios textuales/discursivos en la década de 1980, fue introducido el concepto de acontecimiento por el análisis del discurso (AD) de Pêcheux. Desde los años 2000, otras perspectivas teóricas, cómo la semántica del acontecimiento, se apropiando, a su manera, del referido concepto del $\mathrm{AD}$, correlacionan la enunciación como un acontecimiento de naturaleza histórico-social con la lengua (el sistema). Una tercera corriente de estudios discursivos, la semiótica de la Escuela de Paris, específicamente en su vertiente tensiva, también desarrolla, a su manera, otra noción de acontecimiento: algo de la orden del inesperado y del impactante. Así, en ese artículo, se busca reunir los puntos comunes acerca de los conceptos de acontecimiento desde las referidas teorías, pero sobremodo tiene el objetivo de despegar sus diferencias conceptuales y epistemológicas.

Palabras clave: Acontecimiento. Análisis del discurso. Semántica del acontecimiento. Semiótica tensiva.

\section{INTRODUÇÃO}

Desde pelo menos 1983, com a publicação de Le discours: structure ou événement? [O discurso: estrutura ou acontecimento], última obra de Michel Pêcheux, as teorias do texto e do discurso têm se debruçado sobre a temática do acontecimento, cada qual, evidentemente, à sua maneira. Neste artigo, pretendemos discutir o conceito de acontecimento por três vias teóricas: a análise do discurso francesa (pêcheutiana) doravante $\mathrm{AD}$-, a semântica do acontecimento (cf. GUIMARÃES, 2002a; 2002b) e a semiótica tensiva (cf. FONTANILLE; ZILBERBERG, 2001; ZILBERBERG, 2011), atual desdobramento da semiótica da Escola de Paris, também conhecida como semiótica greimasiana, em homenagem a seu maior expoente, A. J. Greimas.

Para iniciar a discussão, é preciso definir o que ordinariamente se entende por acontecimento. O dicionário Houaiss (HOUAISS; VILLAR, 2001) designa o termo da seguinte maneira: (1) "o que acontece; fato, ocorrência"; (2) "o que acontece ou se realiza de modo inesperado; acaso, eventualidade", (3) ou, ainda: "pessoa ou fato digno de nota, que produz viva sensação ou constitui grande êxito; sucesso". Embora acontecimento tenha sido, majoritariamente, o item lexical escolhido para traduzir événement em obras da área traduzidas para o vernáculo, o termo de mesma raiz latina em português é evento, definido pelo mesmo dicionário como "acontecimento geralmente observável; fenômeno". Salienta-se, dessa forma, que tanto o primeiro quanto o segundo termo se referem a uma ideia central e unificadora: "o que ocorre". Nesse sentido, ao conceito de acontecimento subjaz uma ideia mais abstrata que é a de ruptura que incide num continuum e que, por isso, marca uma anterioridade e uma posterioridade.

Entretanto, para além de somente reunir os pontos em comum acerca da noção de acontecimento, o objetivo principal deste artigo é promover um diálogo mais amplo entre o que cada uma das teorias supracitadas entende por esse conceito. Assim, este texto, de natureza sobretudo teórico-epistemológica, estrutura-se desta maneira: primeiramente, introduzimos algumas noções de AD para aí localizar o conceito de acontecimento cunhado por Pêcheux (2002). Em seguida, mostramos as contribuições e diálogos da 
semântica do acontecimento com a $\mathrm{AD}$ em torno do referido conceito para, em terceiro lugar, expormos de que maneira a semiótica tensiva concebe a noção de acontecimento.

Assim, serão levantadas as consonâncias, mas, principalmente, serão salientadas as dissonâncias conceituais e epistemológicas que encampam o conceito de acontecimento na $\mathrm{AD}$, na semântica do acontecimento e na semiótica tensiva.

20 ACONTECIMENTO PELA AD: CONSTITUIÇÃO DO SUJEITO, CONSTITUIÇÃO DO SENTIDO

Antes de tratarmos dos postulados presentes em Le discours: structure ou événement? [O discurso: estrutura ou acontecimento], última obra de Michel Pêcheux, que priorizam a temática do acontecimento, cabe salientarmos a reconfiguração e a reformulação empreendida pela síntese teórica vislumbrada pelo autor na publicação Análise do Discurso: três épocas (PÊCHEUX, 1990 [1983]). Iniciamos nossa exposição por meio da indicação de alguns conceitos essenciais e dos passos importantes empreendidos pelo autor, tendo como premissa a exposiçao do percurso histórico de Pechêux e da Análise do discurso (AD) em três fases de desenvolvimento, tal como organizadas por Santos (2013).

Em torno da afirmação de que Saussure teria ficado sozinho com suas ideias, Michel Pêcheux (1988) analisa a história epistemológica da linguística, fazendo observações sobre as tendências à desconstrução das teorias, conforme a análise das alianças teóricas que se estabeleceram com e contra o linguista genebrino.

Pêcheux compreende a linguagem como materializada na ideologia, tendo a ideologia sua manifestação por meio da linguagem. A partir dos postulados estabelecidos por Saussure (1979), Pêcheux atribui a origem do estabelecimento da linguística como ciência. Para Saussure, a linguística é parte de uma ciência geral, a semiologia, que teria por tarefa "definir o que faz da língua um sistema especial no conjunto dos fatos semiológicos" (SAUSSURE, 1979, p. 24). Assim, no início do século XX, mediante a divulgação dos trabalhos de Saussure, a investigação sobre a linguagem passa a se tornar um estudo científico. A distinção entre linguagem, língua e fala situa o objeto da linguística para Saussure.

Para Saussure (1979, p. 17), a linguagem é "heteróclita e multifacetada, pois abrange vários domínios, é ao mesmo tempo física, fisiológica e psíquica, pertence ao domínio social e individual, não se deixa classificar em nenhuma categoria dos fatos humanos", podendo ser estudada por outras disciplinas. Saussure estabelece a língua como objeto de estudo linguístico; ela é para Saussure, "a parte essencial da linguagem, exterior ao indivíduo; não pode ser modificada pelo falante e obedece às leis do contrato social estabelecido pelos membros da comunidade". A fala não é, para Saussure, objeto da linguística por ser individual, própria ao falante (SAUSSURE, 1979, p. 17).

A partir da dicotomia saussuriana língua/fala, cuja problemática ausenta-se da perspectiva de estudos discursivos, Pêcheux reflete acerca do discurso, entendido como ponto intermediário entre a linguagem e a ideologia. Para Pêcheux, a linguagem materializa-se por intermédio da ideologia, sendo o discurso entendido como efeito de sentido da relação entre linguagem e ideologia. 
Segundo Pêcheux e Fuchs (1990), o quadro epistemológico do campo da AD abrange a articulação entre três regiões do conhecimento científico: o materialismo histórico, a linguística e a teoria do discurso, como teoria explicativa do modo como se processa a historicidade dos processos semânticos. Ainda de acordo com os autores, essas três regiões são atravessadas e articuladas por uma teoria da subjetividade de natureza psicanalítica.

A primeira fase da Análise do Discurso, "AD como exploração metodológica da noção de maquinaria discursivo-textual" (PÊCHEUX, 1983), tem início com a publicação da obra Analyse automatique du discours, em 1969. A obra, com clara influência do materialismo histórico, postula que "a partir da palavra e depois da sintaxe da língua, poderia desenvolver uma máquina capaz de realizar a 'análise automática do discurso"" (SANTOS, 2013, p. 214).

A segunda fase da AD pauta-se, sobretudo, pelo conceito de formação discursiva, conceito produtivo na reformulação que Pêcheux empreende em seu desenvolvimento teórico a partir da articulação entre os conceitos de memória, história e ideologia. A noção de significante com a qual M. Pêcheux trabalha em Semântica e discurso (1988) é bastante próxima da que J. Lacan, relendo Saussure, postula. Em ambos os autores, uma teoria do sujeito é inseparável da noção de significante. Não podemos esquecer que, na base do quadro epistemológico fundador da $\mathrm{AD}$, Pêcheux já previa uma teoria da subjetividade de base psicanalítica.

A ideologia, considerando as formações discursivas, aponta para a necessidade de atribuição de sentidos, interpretação. Orlandi (1996) mostra que é pela ideologia que se organiza a naturalização dos sentidos, já que o movimento contínuo dos processos de significação supõe sua inscrição na materialidade da língua e da memória discursiva (interdiscurso). Assim, com fundamentos discursivos, a $\mathrm{AD}$, enquanto disciplina de "entremeio", arregimenta, por meio da noção de discurso, a noção de ideologia como relação necessária e constitutiva entre linguagem/mundo. Segundo a autora, "a possibilidade mesma da ação mundo-linguagem se assenta na ideologia" (ORLANDI, 1996, p. 28). Assim, a distinção completa entre linguagem e ideologia acarretaria a ausência plena se sentido. Para Orlandi (1996), a lingua como objeto autônomo só permite a análise de seus níveis formais, dos quais podemos mencionar as perspectivas fônica, morfológica e sintática. A AD concebe a perpectiva do sujeito e do sentido da linguagem mediante a noção de exterioridade, não concebida como um "fora do texto", mas na maneira como os sentidos trabalham conjuntamente no texto em sua discurvidade.

Desse modo, a distinção que Orlandi (1996) faz entre ordem e organização da língua merece menção, uma vez que, para a autora, ser trabalhado pela língua diz respeito à entrada do sujeito em um mundo já dotado de sentidos que o antecedem. Nessa concepção, o sujeito está na língua porque está sendo trabalhado pela língua. Se ele é envolto pelas redes significantes, essas tanto podem articular como desorganizar sua inserção no simbólico. Dentro desse princípio, a relação imaginária do sujeito com a transparência dos sentidos ora se define pelas evidências da realidade daquilo que lhe é dado falar, ver, ouvir, pensar, apagando o fato de que o sujeito resulta de um processo; ora se define pelo que se instaura como sendo uma ordem própria do significante, desarticulando, assim, na realidade imaginária, a identificação com o outro: as repetições (paráfrases), deslocamentos (processos metafóricos) e a multiplicidade (polissemia). 
A AD define-se, portanto, como teoria e método de investigação que busca instaurar nos entremeios textuais uma leitura que permite liberar os sentidos do discurso por meio da sua materialidade, compreendida como o encontro do histórico com o linguístico. A história está posta não pela simples cronologia dos fatos, mas por sua condição de produção: a historicidade se faz reconhecer no texto.

Nessa cronologia, merece destaque a terceira fase da $\mathrm{AD}$, tendo o interdiscurso como característica fundamental. Pêcheux (1990) inclui a noção de interdiscursividade (como designação da exterioridade própria a uma formação discursiva. Merece destaque, ainda, o conceito de memória (PÊCHEUX, 1999), em correspondência a um salto teórico em relação aos primeiros trabalhos, de modo a apresentar um deslocamento entre o sujeito histórico e o analista do discurso.

\begin{abstract}
De fato, a questão do papel da memória permitiu um encontro efetivo entre temas a princípio bastante diferentes. Esta questão conduziu a abordar as condições (mecanismos, processos...) nas quais um acontecimento histórico (um elemento histórico descontínuo e exterior) é suscetível de vir a se inscrever na continuidade interna, no espaço potencial de coerência próprio a uma memória. Memória deve ser entendida aqui não no sentido diretamente psicologista da "memória individual", mas nos sentidos entrecruzados da memória mítica, da memória social inscrita em práticas, e da memória construída do historiador. (PÊCHEUX, 1999, p. 49-50)
\end{abstract}

Dessa maneira, temos em AD o desenvolvimento do conceito de memória como modelo de trabalho do analista, que deve dar conta de que "a memória suposta pelo discurso é sempre reconstruída na enunciação" (ACHARD, 1999, p. 17). A memória recontrói-se, portanto, pela construção do interdiscurso por meio dos já-ditos.

Assim, temos em Pêcheux (1999, p. 50-57) o acontecimento discursivo tomado enquanto ruptura da memória recorrente por meio do interdiscurso.

\begin{abstract}
A certeza que aparece, em todo caso, no fim desse debate é que uma memória não poderia ser concebida como uma esfera plena, cujas bordas seriam transcendentais históricos e cujo conteúdo seria um sentido homogêneo, acumulado ao modo de um reservatório: é necessariamente um espaço móvel de divisões, de disjunções, de deslocamentos e de retomadas, de conflitos de regularização... Um espaço de desdobramentos, réplicas, polêmicas e contra-discursos. (PẾCHEUX, 1999, p. 56)
\end{abstract}

Orlandi (2001), ao retomar a perspectiva das condições de produção e do interdiscurso, expõe as características da memória, pensada em relação ao discurso. Assim, por memória discursiva compreende-se o interdiscurso; "o saber discursivo que torna possível todo dizer e que retoma sob a forma do pré-construído, o já dito que está na base do dizível, sustentando cada tomada de palavra" (ORLANDI, 1999, p. 31). Assim, segundo a autora, por meio da imbricação entre o interdiscurso (o já dito - memória discursiva) e o intradiscurso (discurso em enunciação), constitui-se o dizível.

A reconfiguração teórica empreendida por Pêcheux, tal como demonstrada por Santos (2013, p. 227), estabelece a heterogeneidade e a instabilidade das formações discursivas na relação entre o intradiscurso e o interdiscurso. $\mathrm{O}$ sujeito do discurso passa 
a caracterizar-se pela ruptura, pelo desarranjo, "dependente de uma relação espaçotemporal e de produção de sentidos no interior do discurso" (SANTOS, 2013, p. 231).

O acontecimento discursivo engloba o embate entre a atualidade e a memória que não estabelece uma recorrência repetível, mas, sim, uma ressignificação. Enquanto a memória procura estabelecer uma regularidade enunciativa, o acontecimento discursivo caracteriza-se, contrariamente, como sua irrupção. "O sentido, então, emerge da materialidade discursiva em relação com a história e com o acontecimento, uma vez que a materialidade linguística em si não dá conta do seu sentido" (SANTOS, 2013, p. 231).

Destacamos a publicação Discurso: estrutura ou acontecimento (PÊCHEUX, 2002). Para Pêcheux (2002), a noção de acontecimento, dentro dessa concepção, não é apenas fato exterior ao discurso, mas parte constitutiva da discursividade. $\mathrm{O}$ autor exemplifica o que chama de acontecimento no seguinte trecho: "Paris, 10 de maio de 1981, 20 horas (hora local): a imagem, simplificada e recomposta eletronicamente, do futuro presidente da República Francesa aparece nos televisores... Estupor (de maravilhamento ou de terror): é a de François Mitterand!" (PÊCHEUX, 2002, p. 19). O acontecimento jornalístico remete a um acontecimento de natureza sociopolítica simultaneamente transparente (pelo resultado nas urnas) e opaco, uma vez que, por meio de enunciados que remetem ao mesmo fato (a vitória de Mitterand), gera significações distintas. Como exemplo, Pêcheux (p. 20) cita: "F. Mitterand é eleito presidente da República Francesa", "A esquerda francesa leva a vitória eleitoral dos presidenciáveis" e "A coalização socialista-comunista se apodera da França". Nota-se que os primeiros enunciados constroem, pelo discurso, uma ocorrência desejável, enquanto o último, indesejável. Ao acontecimento descrito, junta-se o clamor popular On a gagné [Ganhamos] cantado em uníssono na Praça da Bastilha, o qual é perpassado pelo grito coletivo de torcedores de competições esportivas "materializando a festa da vitória da equipe, tanto mais intensamente quanto ela era mais improvável..." (p. 21).

Assim, o enunciado On a gagné passa a sobredeterminar o acontecimento, de modo, segundo Pêcheux (2002, p. 22), a sublinhar sua "equivocidade". Noutros termos, para o autor, abre-se uma questão teórica: a do "estatuto das discursividades que trabalham um acontecimento, entrecruzando proposições de aparência logicamente estável, suscetíveis de respostas unívoca (é sim ou não, é x ou y, etc.) e formulações irremediavelmente equívocas" (p. 28). Ao ser, portanto, discursivizado, o acontecimento torna-se opaco. É, pois, atravessado pela historicidade, pela ideologia, pela posição de quem fala.

\section{ACONTECIMENTO PELA SEMÂNTICA DO ACONTECIMENTO: O FUNCIONAMENTO DA LÍNGUA NA SUA HISTORICIDADE}

A abordagem semântica desenvolvida por Guimarães (2002a), ao propor um dispositivo teórico de análise que nos permite analisar o discurso em relação aos processos de significação que o constituem, por meio de seus mecanismos de funcionamento, pretende abrir uma relação com a $\mathrm{AD}$, de modo específico e, em geral, 
com as teorias do sujeito. A semântica do acontecimento proposta por Eduardo Guimarães se apresenta como o resultado de filiações teóricas entre a escola francesa de $\mathrm{AD}$ e a semântica argumentativa em moldes ducrotianos; define-se por estabelecer um diálogo entre as análises semânticas do nome próprio, a teoria dos atos de fala e a AD. Ao considerar que a exterioridade discursiva não abandona a especificidade do sistema linguístico, a semântica do acontecimento se filia, por um lado, aos trabalhos de Frege, Russell, Searle, Grice, Bréal, Bally, Benveniste e Ducrot e, por outro lado, aos estudos de Pêcheux, Authier-Revuz, Henry e Orlandi. A semântica do acontecimento marca, no entanto, sua especificidade em relação a esses teóricos, como destacaremos.

Autores como Benveniste e Ducrot, apesar de reintroduzirem em seus estudos linguísticos a exterioridade, concebem a história cronologicamente. Guimarães, ao incluir a história, procura constituir uma semântica enunciativa que considera a representação do sujeito na constituição do sentido; considera, assim, que o sentido de um enunciado são os efeitos de sua enunciação, segundo as condições histórico-enunciativas em que aparece.

Guimarães (2002a) considera que a linguagem fala de algo e o que se diz é construído na e pela linguagem. Ao definir a semântica do acontecimento como a responsável por uma análise do sentido da linguagem, centrada no estudo da enunciação, do acontecimento do dizer, encontra impedimentos quanto à posição de Saussure no Curso de linguística geral (1979). Saussure, ao definir a língua como objeto de estudo da linguística, deixa para a fala o individual, o subjetivo; nessa concepção, são as relações internas que dão o caráter definidor para a língua, e o que há de significação no Curso é o que há de codificado como significado. A semântica do acontecimento é um gesto de incluir o excluído saussuriano, uma vez que considera, além do sistema linguístico (a língua), a discursividade (historicidade da língua). Para Guimarães, a significação está justamente no que Saussure definiu como exterior; considera, portanto, a significação a partir da questão da exterioridade da língua (o mundo, o sujeito, o referente, a história) que é uma exterioridade discursiva, ou seja, tomando o conceito de interdiscurso a partir do que propõe Orlandi, é o "interdiscurso, que se define como o conjunto do dizível, histórica e linguisticamente constituído" (ORLANDI, 1999, p. 89).

A linguagem, nessa perspectiva, passa a ser entendida como um fenômeno histórico que funciona segundo um conjunto de regularidades socialmente construídas, que se cruzam e podem ir permitindo mudanças nos fatos sem que isso possa ser visto como desvio ou quebra de uma regra. Conforme o autor, "quanto a uma língua, diríamos que ela é uma dispersão de regularidades linguísticas que a caracteriza, necessariamente, como fenômeno social e histórico" (GUIMARÃES, 2002b, p. 17).

A semântica do acontecimento propõe correlacionar a enunciação, como um acontecimento de natureza histórico-social, com a língua; o enunciado, nessa concepção, se constitui como elemento de uma prática social, em que os sentidos são determinados pelas distintas posições-sujeito ocupadas pelo indivíduo e caracterizadas histórica e socialmente no acontecimento enunciativo. Desse modo "a significação é determinada pelas condições sociais de sua existência” (GUIMARÃES, 1995, p. 66). Para Guimarães (1999), o acontecimento histórico não está num presente de um antes e de um depois no tempo. A significação é, portanto, histórica, não no sentido cronológico, historiográfico, 
em que os fatos significam um acontecimento social, determinados apenas no tempo, constituindo um fato sempre único e irrepetível, mas no sentido de que a história é constituída do presente da enunciação. Dessa forma, a enunciação, entendida como a língua posta em funcionamento pelo interdiscurso no acontecimento, torna-se o ponto central da constituição da semântica do acontecimento, uma vez que o acontecimento relação do interdiscurso com as regularidades da língua - torna-se constitutivo de sentido. Observamos, assim, a correlação entre os termos discurso, enunciação sentido e significação, caros à $\mathrm{AD}$.

Nessa concepção, o sentido está posto como uma questão enunciativa em que a enunciação é constituída de uma historicidade entendida como a determinação pelas condições sociais de sua existência; o sentido constitui-se discursivamente a partir de um acontecimento enunciativo. Assim, Guimarães (1995, p. 85), ao já conceber uma semântica histórica da enunciação que "se constitui no lugar em que trata a questão da significação ao mesmo tempo como linguística, histórica e relativa ao sujeito que enuncia", considerando que a linguagem funciona na relação língua/interdiscurso, estabelece um diálogo com a $\mathrm{AD}$.

Na semântica do acontecimento, uma semântica fundamentada na historicidade da língua, o sujeito se constitui na e pela linguagem. Para Guimarães (2011):

\begin{abstract}
Minha posição enquanto historiador da Ciência é compreender os sentidos dos acontecimentos humanos; uma compreensão dos fatos tomados como acontecimento. Enquanto historiador, no entanto, não me ocupo de fatos singulares, não me ocupo das singularidades das coisas, e, sim da especificidade dos fatos, ou seja, enquanto elemento de uma série, algo constituído por uma especificidade é acontecimento. O acontecimento, no entanto, apresenta uma temporalidade própria, não se deixa tomar por uma cronologia dos fatos (Comunicação oral) ${ }^{1}$.
\end{abstract}

Assim, a perspectiva teórica da semântica do acontecimento, formulada por Guimarães (2002a), concebe o objeto como uma exterioridade produzida pela linguagem, todavia não se reduz ao que se fala dela, pois é objetivada pelo confronto de discursos; isso se dá no sentido em que o objeto é construído por uma relação de discursos. A sua materialidade é esse confronto: a relação de sentido é uma relação instável entre a linguagem e o objeto, pois o cruzamento de discursos não é estável, é, ao contrário, exposto à diferença.

Para a semântica do acontecimento, não é a uma realidade preexistente que as palavras construam o sentido em si mesmas, apesar de toda relação de linguagem estar, materialmente, exposta ao real. Nesse sentido, Guimarães (2007) desenvolve um procedimento de interpretação específico, o de Domínio Semântico de Determinação (DSD), e propõe um estudo do sentido em que a sinonímia, a homonímia, a antonímia, a hiperonímia, a polissemia e a ambiguidade não sejam tomadas referencialmente. Considera-se que a relação fundamental da significação são as relações de determinação

\footnotetext{
${ }^{1}$ II Jornada Estudos da Linguagem - Instituto de Letras, UFF - 2011 - Palestra: A história das ideias linguísticas: um acontecimento decisivo no processo de gramatização brasileira do português, de Eduardo Guimarães - UNICAMP.
} 
semântica e que há uma relação de sentidos entre as palavras, um externo à linguagem que deve ser levado em conta não a partir da denotação, mas da relação de uma palavra a outra palavra no texto em que elas ocorrem.

Admitindo essa concepção, os enunciados, ao mesmo tempo que produzem um efeito de unidade no texto, possuem uma independência relativa quanto ao texto porque há algo na significação do enunciado que tem a ver justamente com o texto no qual se integra, relacionando-se com outros enunciados. Logo, os sentidos não se fecham nos enunciados e os textos só funcionam pelo efeito de totalidade, de unidade, pois o enunciado se desintegra, mas o texto não se divide.

Só é possível pensarmos as questões de significação a partir do DSD se considerarmos, além das relações das palavras nos textos em que aparecem, os fatores externos à sua formulação, como o interdiscurso, a ideologia, os locutores: o sentido em sua historicidade, com suas condições de produção. A designação de uma palavra é uma relação de palavra a palavra, por um processo de identificação, não porque as coisas existem, mas porque significam. Assim, pensar o DSD, segundo Guimarães (2009), é considerar o sentido construído na enunciação, historicamente, porque as palavras significam de acordo com as relações de determinação semântica que se constituem no acontecimento enunciativo, pelo modo como se relacionam com outras no texto.

\title{
40 ACONTECIMENTO PELA SEMIÓTICA: PAROXISMO DA AFETIVIDADE, NEGAÇÃO DO DIZER
}

Antes de falarmos do conceito de acontecimento no âmbito da semiótica da Escola de Paris, é importante mencionar que essa teoria, considerando suas bases saussurianas e hjelmslevianas, também trata da exterioridade discursiva.

Segundo Barros (2009, p. 352):

\begin{abstract}
A semiótica discursiva não trata a "exterioridade" discursiva como "exterioridade", ou seja, como algo exterior ao texto ou ao discurso, mas não deixa de examinar, sob outro prisma e com outros nomes, aquilo que, em outros quadros teóricos, é denominado "exterioridade", pois, para a teoria semiótica, os procedimentos que constroem os sentidos de um texto são de dois tipos: procedimentos linguístico-discursivos e relações com a sociedade e a História.
\end{abstract}

Conforme Barros (2009, p. 352), para abordar o que é exterior ao texto/ao discurso, isto é, para estabelecer uma relação entre texto e contexto ("relações histórico-sociais, que participam da construção dos sentidos dos textos"), a semiótica atua metodologicamente de três formas: $\left(1^{\mathrm{a}}\right)$ pela análise de percursos temáticos e figurativos "que revelam, de alguma forma, as determinações histórico-sociais inconscientes"; $\left(2^{\mathrm{a}}\right)$ pelas relações intertextuais e interdiscursivas que o texto em análise estabelece com outros textos; $\left(3^{\mathrm{a}}\right)$ pelas relações entre a semiótica da língua e a semiótica do mundo natural (ou outros sistemas de significação). Dessa forma, a priori, seria possível a abordagem do acontecimento, à luz da semiótica de Greimas e colaboradores, a partir das três formas mencionadas por Barros (2009). 
Assim, se, para a AD, o acontecimento é o sentido decorrente da exterioridade discursiva que permeia o discurso, o interdiscurso, a memória, o já dito, as condições de produção, entendendo-se a "exterioridade" como uma distinção de ordem (discursiva) e organização (textual); se, para a semântica do acontecimento, o acontecimento é o ponto de interseção entre o intra e o extradiscurso; a semiótica tensiva, por sua vez, concebe o acontecimento sobretudo de forma intradiscursiva, estrutural da enunciação, uma vez que, conforme será demonstrado, para Zilberberg (2011, p. 12), a semiótica tensiva apresentase justamente como uma "gramática do afeto".

Para darmos prosseguimento à abordagem do acontecimento em semiótica tensiva, é preciso fazer algumas considerações a respeito da teoria. Esta, grosso modo, concede espaço privilegiado ao contínuo e à afetividade no discurso. Desse modo, pela semiótica clássica - que teve como núcleo, por muito tempo, a noção de narratividade - a significação se constitui a partir de unidades discretas, haja vista o percurso gerativo de sentido. Cabe ressaltar, entretanto, na esteira de Greimas e Fontanille (1993, p. 10, 15), que a essa discretização subjaz um continuum, que já é uma potencialidade de sentido. Desse modo, a semiótica tensiva constitui-se de forma complementar e não em substituição à semiótica clássica. É contundente, assim, a seguinte asserção de Zilberberg (2011, p. 16): “a 'casa do sentido' é vasta o bastante para acolher tanto o contínuo, quanto o descontínuo, mesmo porque nem este nem aquele fazem sentido por si mesmos, mas apenas por sua colaboração".

No que se refere à continuidade, a vertente tensiva apresenta a noção de gradação, que permite a análise de certos fenômenos cuja principal característica não é a oposição. A título de exemplo de oposição, no nível fundamental, podemos citar vida vs. morte, da semiótica clássica. No caso da semiótica tensiva o que é posto em relevo é a diferença em algum grau, ou, nas palavras de Zilberberg (2011, p. 14), o "intervalo":

Dizer que [a] se opõe a [b] equivale a dizer que [a] se afasta "em maior ou menor medida" de [b], e que esse afastamento tem de ser avaliado pela simples razão de que ele corresponde à sua própria definição! Tal escolha leva a conceber, entre [a] e [b], um vão, um intervalo, ocupando-o ou preenchendo-o de alguma maneira (p. 22).

Quanto à afetividade, a semiótica tensiva considera o inteligível e o sensível duas dimensões que se implicam e se condicionam mutuamente num processo em que uma não tem existência própria sem a outra. A teoria, ademais, concede primazia ao afeto, à intensidade, que é regente da extensidade. Aquela, relativa aos estados de alma, dirige, governa a extensidade: os estados de coisas, o inteligível. Assim, a tensividade é o lugar imaginário em que a intensidade se une à extensidade. Portanto, o sentido é, de certo modo, dependente da afetividade. Cabe salientar, entretanto, que o afeto não pressupõe o discurso, como no caso da psicanálise, mas lhe é concomitante. Zilberberg (2011, p. 12) fala, conforme se mencionou, em uma "gramática do afeto". Logo, por tal ponto de vista, o afeto é gramaticalizável, pois constitui-se na e pela linguagem.

Para a semiótica tensiva, o cruzamento do eixo da intensidade e da extensidade demarca o espaço tensivo, que recebe e qualifica as grandezas que têm acesso ao campo de presença. Um fato semiótico é condicionado, ou, ainda, só tem existência semiótica no e pelo espaço tensivo da seguinte maneira, conforme demonstra a Figura 1: 


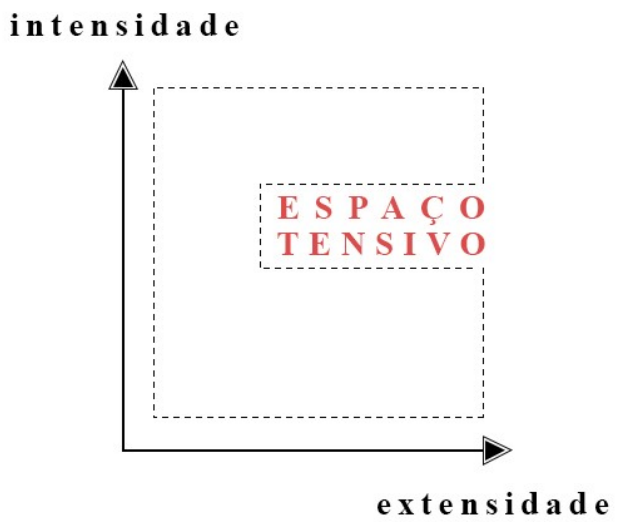

\section{Figura 1 - Espaço tensivo}

Fonte: Elaboração dos autores com base em Zilberberg (2011).

Tal espaço é fundamentalmente complexo, pois é produto da relação necessária entre estados de alma e estados de coisas, o qual se produz, conforme dissemos, pela projeção da intensidade sobre a extensidade. Assim, qualquer ponto dentro do espaço tensivo corresponderá a um fato semiótico que, obrigatoriamente, terá uma valência em termos de intensidade e outra valência em termos de extensidade.

O eixo da intensidade opera por meio dos pares [impactante $v s$. tênue]; o eixo da extensidade, por sua vez, pelos pares [concentrado vs. difuso]. São esses pares que controlam o acesso ao campo de presença. Assim, no que se refere à intensidade, uma grandeza acessa o campo de presença de forma proporcional à quantidade de impacto que carrega consigo e, em termos de extensidade, ela será mais ou menos difusa, a partir das operações de mistura e triagem, conforme pode ser visto na Figura 2:

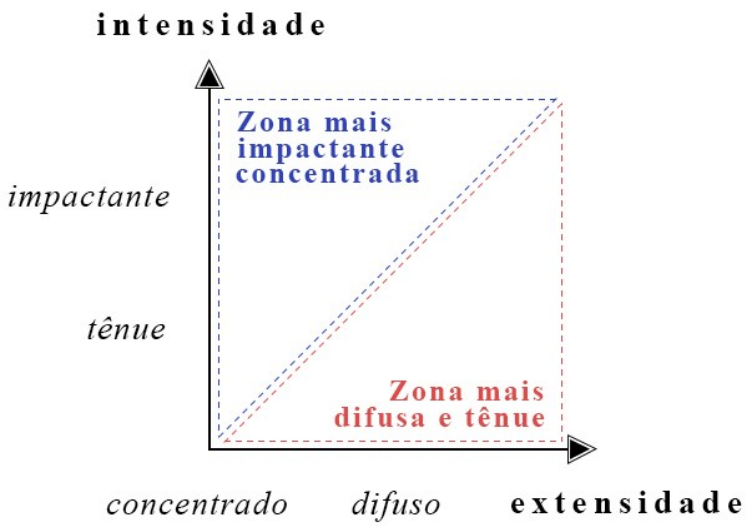

\section{Figura 2 - Áreas do espaço tensivo}

Fonte: Elaboração dos autores com base em Zilberberg (2011).

Assim, quanto mais um fato semiótico tender à concentração, mais ele será guiado pelos valores de absoluto. Por outro lado, quanto mais esse fato tender à difusão, mais ele será governado pelos valores de universo. No caso dos valores de absoluto, entram em jogo as operações de triagem; no caso dos valores de universo, opera-se por mistura.

Tal como aponta Fiorin (2017, p. 158), na semiótica tensiva, as alterações e vicissitudes responsáveis pela alteração do sentido decorrem da instabilidade e da imprevisibilidade, pautada na foria (força motriz), sobredeterminada em três grandezas, ou impulsos: a direção, a posição e o elã.

Tendo sido apresentadas algumas concepções basilares da semiótica tensiva, passemos ao conceito que é considerado seu cerne: o acontecimento. Para Zilberberg (2007, p. 16), “o fato tem por correlato 
intenso o acontecimento. [...] $\mathrm{O}$ acontecimento é o correlato hiperbólico do fato, do mesmo modo como o fato se inscreve como diminutivo do acontecimento". O acontecimento, dessa forma, é raro ao passo que o fato é numeroso. Além disso, o acontecimento é tônico, enquanto o fato é átono. Por fim, o acontecimento não pode ser visado, antecipado, pois, "quando a coisa acontece, já é tarde demais!" (ZILBERBERG, 2011, p. 169, grifos do autor).

O acontecimento é, assim, produto das subdimensões paroxísticas andamento e tonicidade, as quais compõem a dimensão da intensidade. Dito de outro modo, é o fruto da velocidade aguda de um evento com sua energia e força de impacto no sujeito. Andamento e tonicidade agem juntos, perturbando o sujeito por meio de uma "tempestade modal” (ZILBERBERG, 2011, p. 236) instantânea, deixando-lhe apenas um sofrer que se sobrepõe ao agir: "o acontecimento, por ser portador do impacto, manifesta enquanto tal que o sujeito trocou 'a contragosto' o universo da medida pelo da desmedida" (p. 163). Noutros termos, o acontecimento significa levar a afetividade ao auge, e tornar temporariamente a intelecção nula. No que tange às subdimensões da extensidade, a temporalidade é extinta - o tempo fica "fora dos eixos". O mesmo se pode dizer da espacialidade, pois o sujeito, estupefato, vê-se "fincado" no chão, ou, num lapso de tempo, engolido por um buraco negro, retirado de sua própria ambiência.

$\mathrm{Na}$ Figura 3, a seguir, representa-se graficamente o acontecimento, na parte superior esquerda do espaço tensivo, e o exercício, na porção inferior direita:

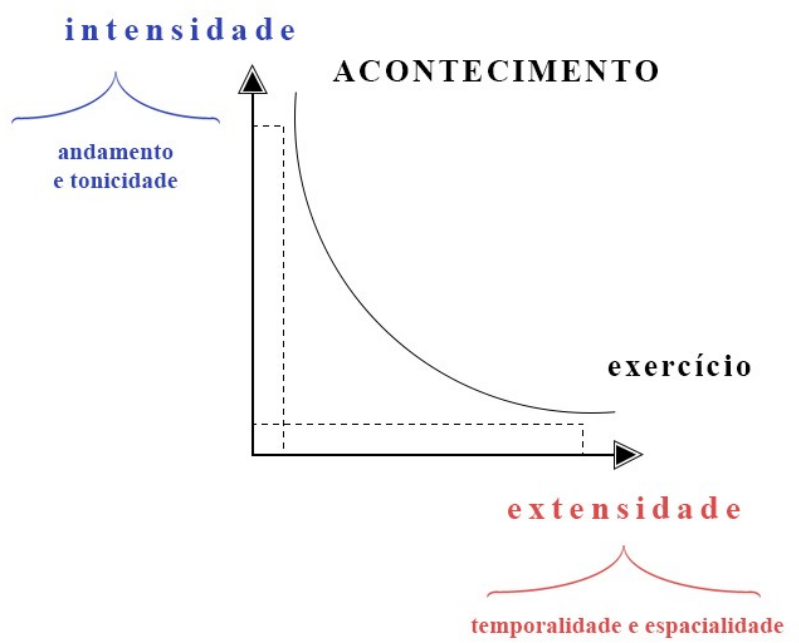

\section{Figura 3 - Acontecimento e exercício}

Fonte: Elaboração dos autores com base em Zilberberg (2011)

A hipótese de acontecimento para Zilberberg é, assim, a "realização súbita e extática do irrealizável" (2011, p. 176); mais precisamente, esse sistema levaria em conta o modo concessivo, oposto ao implicativo, segundo o qual: ainda que não fosse possível, tal coisa aconteceu.

Zilberberg (2007, p. 25) estabelece três modos - eficiência, existência e junção - cujos respectivos termos configuram os estilos discursivos do acontecimento e do exercício. O modo de eficiência designa "a maneira pela qual uma grandeza se instala num campo de presença" (ZILBERBERG, 2007, p. 18). Se a grandeza se instala lentamente, configura-se a modalidade do pervir. Se, ao contrário, penetra abruptamente, tem-se a modalidade do sobrevir. O modo de existência, por sua vez, refere-se à alternância 
entre os pares foco e apreensão. Tais termos se referem ao correlato subjetal dos termos pervir e sobrevir. No caso do foco, há um sujeito operador que age, muito próximo ao sujeito do fazer; não há surpresas, mas relações de pressuposição tais como no esquema narrativo. Na apreensão ocorre o contrário; não se trata mais de um sujeito do fazer, mas um sujeito de estado que sofre, que suporta, que, enfim, é invadido pelo objeto que surge ex abrupto. O modo juntivo, por sua vez, coincide com a sintaxe juntiva e articula o modo implicativo e o modo concessivo:

No caso da implicação, o direito e o fato se respaldam mutuamente. Sua esfera é a da implicação: "se a, então b" e geralmente da causalidade legal. [...] No caso da concessão, o direito e o fato estão em discordância um do outro. Ela tem como emblema a dupla formada pelo embora e pelo entretanto: “embora a, entretanto não b” (ZILBERBERG, 2007, p. 23).

Para Zilberberg (2007, p. 25), o estilo discursivo do acontecimento se define estruturalmente a partir de cada um dos pares dos modos de eficiência, de existência e de junção, a saber: o sobrevir, a apreensão e a concessão. O estilo discursivo do exercício, por sua vez, tem sua estrutura composta pelos termos pervir, foco e implicação, a partir dos modos já mencionados. A seguir, apresentamos de forma esquemática, no Quadro 1, a estrutura do acontecimento e do exercício:

\begin{tabular}{|c|c|c|}
\hline determinados & ACONTECIMENTO & EXERCÍCIO \\
\hline determinantes & & \\
\hline modo de eficiência & sobrevir & pervir \\
\hline \hline modo de existência & apreensão & foco \\
\hline \hline modo de junção & concessão & implicação \\
\hline
\end{tabular}

\section{Quadro 1 - Estrutura do acontecimento e do exercício}

Fonte: Adaptado de Zilberberg (2007, p. 25).

Acontecimento e exercício são, pois, duas grandes orientações discursivas. A primeira corresponderia à problemática do surpreendente, do inesperado, regido por uma lógica concessiva. A segunda, por sua vez, à questão da narratividade que, por anos, foi o principal foco de interesse da semiótica, a qual, por sua vez, é governada pela lógica implicativa. Com efeito, para Zilberberg $(2011$, p. 171) o acontecimento e o esquema narrativo canônico são duas grandes vias possíveis de sentido.

Para agir contra esse programa, o do acontecimento, o discurso atuaria como um contraprograma, uma espécie de frenagem do andamento acelerado, isto é, uma intelecção do que é essencialmente sensível: "O discurso se empenha em refazer aquilo que a exclamação desfez" (ZILBERBERG, 2011, p. 194). Ou, ainda: "O acontecimento significa literalmente a negação do dizer, a negação do discurso. [...] $\mathrm{O}$ acontecimento é antes de tudo um não-sei-o-quê que deixa o sujeito sem voz, sem a sua voz" (ZILBERBERG, 2011, p. 189). Por isso, de acordo com a semiótica tensiva, o discurso depende do acontecimento (mais tônico e concentrado) e do fato (mais átono e difuso) para existir. O discurso, portanto, constrói-se justamente pela sucessão de continuidades e descontinuidades, aumentos e diminuições. 
Neste artigo, apresentamos três conceitos de acontecimento, cada qual à luz de uma teoria: a AD pêcheutiana, a semântica do acontecimento e a semiótica tensiva.

(1) No caso da $\mathrm{AD}$, ao destacarmos a noção de acontecimento e os princípios básicos de reflexão da disciplina, procuramos aprofundar certas conexões teóricas indicadas por Pêcheux a respeito de uma de suas teses centrais: a questão da constituição do sujeito encontra-se ligada à da constituição do sentido e ambas precisam ser pensadas/articuladas à questão dos processos de interpelação-identificação que atravessam o sujeito. O discurso, tal como foi postulado por Pêcheux (1988) e tem sido minuciosamente discutido e analisado por Orlandi (1996), é concebido como efeito de sentido entre locutores, o que remete a uma compreensão de linguagem como prática simbólica, uma prática que se constitui pela via do significante e que se encontra na gênese do processo de constituição do sujeito. $\mathrm{O}$ acontecimento instaura um já-dito e pressupõe a existência de um pré-construído que compõe o jogo discursivo, ou seja, a construção de sentidos pressupõe um acontecimento histórico presente na memória discursiva; o sentido é, portanto, indissociável das práticas sócio-históricas e os acontecimentos discursivos se instauram como enunciações que revelam rupturas que apresentam uma temporalidade específica. Desse modo, o discurso, definido como "efeito de sentidos entre locutores" (PÊCHEUX apud ORLANDI, 1999, p. 21), é o lugar de contato entre língua e ideologia; não é, portanto, algo que apenas transmite informações de forma clara e objetiva. Nessa perspectiva, a materialidade linguística deve ser pensada na sua constituição discursiva e o processo discursivo deve ser definido pelas condições de produção de sua enunciação, pelos efeitos do cruzamento de diversos discursos, e das várias posições do sujeito. Para Orlandi (1990), são as relações entre discursos que dão a particularidade que constitui todo discurso; assim, as condições em que os sentidos são produzidos são constituídas pelas formações discursivas, ou seja, pelas diferentes regiões que recortam o interdiscurso, refletindo as diferentes formações ideológicas e o modo como as posições-sujeito, os lugares sociais por eles representados, constituem sentidos diferentes. Dessa forma, o acontecimento da enunciação deve ser entendido como discursivo. Ou seja, são todas essas condições de produção que irão constituir o sentido da enunciação.

(2) Considerando os conceitos teóricos e descritivos propostos e desenvolvidos pela semântica do acontecimento, objetivamos evidenciar o conceito de acontecimento proposto por Guimarães (2002), que toma a enunciação como um acontecimento histórico, em que o sentido está posto a partir da consideração de que a enunciação é determinada pelas condições sociais de sua existência. A enunciação é considerada por Guimarães, tal como apontado, como um acontecimento de linguagem que se faz pelo funcionamento da língua. Esse funcionamento da língua se faz pela relação entre língua e falante, "pois os falantes são pessoas determinadas pelas línguas que falam; são sujeitos da língua enquanto constituídos por este espaço de línguas e falantes" (GUIMARÃES, 2002, p. 18). É fundamental enfatizar, nessa concepção, o espaço em que a palavra e as línguas regulam ou disputam um lugar, atravessadas pelo político; para o autor, o falante é uma figura política constituída pelos espaços de enunciação. Esse atravessamento pelo 
político instaura a divisão da língua e, nesses espaços de disputa que se constituem pela equivocidade própria do acontecimento, encontramos falantes divididos pelo seu modo de pensar, pelo seu direito de dizer. Essa equivocidade, segundo o autor, dá-se a partir de uma deontologia (uma moral e uma ética que regula, organiza e distribui os papéis sociais) e de um conflito oriundo da própria deontologia, provocando redivisão e disputa constante pelos papéis sociais. Ao incluir a história, Guimarães (1995) trata a questão do sentido como uma questão enunciativa em que a enunciação é vista historicamente; assim, o sentido são os efeitos da memória, das posições de sujeito, do cruzamento de discursos no acontecimento, no presente do acontecimento. Com a inserção da história/historicidade nos estudos semânticos formais, Guimarães (1993) concebe a enunciação considerando a noção de acontecimento e sua relação com a língua. Nesse sentido, a enunciação passa a ser "um acontecimento de linguagem, perpassado pelo interdiscurso, que se dá como espaço de memória no acontecimento. "É um acontecimento que se dá porque a língua funciona ao ser afetada pelo interdiscurso" (GUIMARÃES, 1993, p. 70; grifos nossos). Assim, a enunciação deixa de ser uma organização intelectual do sujeito, entendido como fonte, origem dos sentidos produzidos, e tampouco se reduz ao contexto em que se fala; a enunciação não diz respeito apenas à situação.

(3) No âmbito da semiótica tensiva, o acontecimento, de acordo com Zilberberg (2007), é o paroxismo da intensidade, do afeto. Ainda no que diz respeito às singularidades do modelo tensivo, merece destaque a introdução dos conceitos de implicação e concessão. O primeiro refere-se à gramaticalidade das regras e o segundo aos enunciados de ruptura, que remetem ao acontecimento caracterizado pela realização de um programa, desastroso ou salvador, para o sujeito, conforme o caso (ZILBERBERG, 2006, p. 204). O discurso do exercício, próprio à lógica implicativa, opõe-se ao discurso do acontecimento. O acontecimento, por sua vez, instaura um programa dado como irrealizável, a que se contrapõe um contraprograma que leva a termo a sua realização mediante o âmbito contratual (ZILBERBERG, 2006, p. 148). Ao se situar no eixo do exercício, ou seja, ao pervir e à lentidão, próprias à lógica implicativa, ela se contrapõe ao acontecimento, pautado pela exclamação própria ao sobrevir. Faz-se, assim, a necessidade de um tempo lento a fim de aplacar a perturbação sofrida pelos sujeitos diante da emergência do acontecimento. $\mathrm{O}$ acontecimento concebido pela semiótica tensiva possui um caráter sobretudo intradiscursivo, estrutural, constituindo-se a partir do modo de eficiência, pelo sobrevir; pelo modo de existência, pela apreensão; e pelo modo de junção, pela concessão.

Ao fim deste percurso, pudemos observar que, não obstante as distintas bases epistemológicas e filiações teóricas de cada corrente aqui abordada, a noção de ruptura encontra-se presente como condição mesma do acontecimento e do sentido. Considerando-se a diferenciação conceitual entre a noção de acontecimento enunciativo e acontecimento discursivo feita por Indursky (2008), podemos afirmar que o acontecimento, nas três vertentes teóricas aqui tratadas, é discursivo. Para distinguir tais conceitos, a autora trabalha com a noção de formação discursiva (FD). No acontecimento discursivo, a ruptura se define marcando uma nova forma-sujeito, isto é, as posiçõessujeito não são iguais. No acontecimento enunciativo, a FD se mantém, a ruptura não se 
instaura, uma vez que não se produz uma nova FD; há, no entanto, dentro da mesma FD, posições-sujeito diferentes que determinam sentidos diferentes, que implicam maneiras diferentes de se conceber as posições-sujeito e sua relação com a ideologia.

\section{CONSIDERAÇÕES FINAIS}

Neste artigo, procuramos estabelecer um diálogo entre três teorias - a AD pêcheutiana, a semântica do acontecimento e a semiótica tensiva - em torno do conceito de acontecimento. Em que pesem as especificidades de cada corrente, concluímos que, nos três casos, trata-se de um acontecimento discursivo, uma vez que a todas elas subjaz a noção de ruptura. Assim, para a $\mathrm{AD}$, o acontecimento é sobretudo um acontecimento (inter)discursivo. Para a semântica do acontecimento, o acontecimento se refere à interseção entre o intra e o extradiscursivo, da qual emana o sentido. E, por fim, para a semiótica tensiva, sendo o acontecimento concebido em termos estruturais, imanentes, trata-se também de um acontecimento discursivo, na medida em que o discurso ${ }^{2}$, em semiótica, refere-se ao processo semiótico, concebido como enunciado cuja análise se refere ao plano do conteúdo dos textos. O acontecimento semiótico é, pois, o que se sobrepõe a um enunciado de estado.

\section{REFERÊNCIAS}

ACHARD, P. Memória e produção discursiva do sentido. In: ACHARD, P. et al. Papel da memória. Campinas (SP): Pontes, 1999. p. 11-17.

BARROS, D. L. P. de. Uma reflexão semiótica sobre a “exterioridade” discursiva. Revista Alfa, v. 53, n. 9, p. 351-364, 2009.

DUCROT, O. O dizer e o dito. Tradução de Eduardo Guimarães. Campinas: SP, 1987.

FIORIN, J. L. Semiótica Tensiva. In: FIORIN, J. L. (Org.) Novos caminhos da Linguística. São Paulo: Contexto, 2017.

FONTANILlE, J.; ZILBERBERG, C. Tensão e significação. Tradução de I. C. Lopes; L. Tatit e W. Beividas. São Paulo: Humanitas, 2001.

GREIMAS, A. J.; FONTANILLE, J. Semiótica das paixões: dos estados de coisas aos estados de alma. Tradução de M. J. R. Coracini. São Paulo: Ática, 1993.

GREIMAS, A. J.; COURTÉS, J. Dicionário de semiótica. São Paulo: Contexto, 2008.

GUIMARÃES, E. Palestra: A história das ideias linguísticas: um acontecimento decisivo no processo de gramatização brasileira do português. In: JORNADA ESTUDOS DA LINGUAGEM, 2., Niterói, 2011. Universidade Federal Fluminense, Instituto de Letras, 2011.

GUIMARÃES, E. A enumeração: funcionamento enunciativo e sentido. Cadernos de Estudos

Linguísticos, Campinas, v. 51, n. 1, p. 49-68,. Jan./Jun. 2009.

GUIMARÃES, E. Domínio semântico de determinação. In: GUIMARÃES, E.; MOLLICA, M. C. (Org.) A palavra: forma e sentido. Campinas: Pontes Editores/ RG Editores, 2007. p. 77-96.

GUIMARÃES, E. Semântica do acontecimento. Campinas: Pontes, 2002a.

\footnotetext{
${ }^{2}$ A concepção de discurso, cara à teoria semiótica, pode ser definida, conforme Greimas e Courtés (2008, 145), "de um lado, às dicotomias fundamentais língua/fala, sistema/processo, competência e performance e, de outro, ser situada relativamente à instância da enunciação".
} 
GUIMARÃES, E. Texto e argumentação. 3. ed. Campinas: Pontes, 2002b.

GUIMARÃES, E. Um mapa e suas ruas. DL/IEL/LABEURB - UNICAMP - Campinas, 1999.

GUIMARÃES, E. Os limites do sentido. Campinas: Pontes, 1995.

GUIMARÃES, E. Independência e Morte. In: ORLANDI, E. (Org.). Discurso fundador. Campinas: Pontes, 1993.

HOUAISS, A.; VILLAR, M. de S. Dicionário Houaiss da língua portuguesa. Rio de Janeiro: Objetiva, 2001.

INDURSKY, F. Unicidade, desdobramento, fragmentação: a trajetória da noção de sujeito na Análise do Discurso. In: MITTMANN, S.; GRIGOLETTO, E.; CAZARIN, E. A. (Org.). Práticas discursivas e identitárias: sujeito e língua. Porto Alegre: Nova Prova, 2008. p. 9-33.

ORLANDI, E.; GUIMARÃES, E. Unidade e dispersão: uma questão do texto e do sujeito. In:

ORLANDI, E. Discurso e leitura. 4. ed. Campinas: Cortez Editora, 1999.

ORLANDI, E. Análise de discurso: princípios e procedimentos. Campinas: Pontes,1999.

ORLANDI, E. Interpretação: autoria, leitura e efeitos do trabalho simbólico. Rio de Janeiro: Vozes, 1996.

ORLANDI, E. Terra à vista. São Paulo: Cortez/Editora da Unicamp, 1990.

PÊCHEUX, M. Semântica e discurso: uma crítica à afirmação do óbvio. Campinas: Editora da UNICAMP, 1988.

PÊCHEUX, M. O discurso: estrutura ou acontecimento. Campinas: Pontes, 2002.

PÊCHEUX, M. Papel da memória. In: ACHARD, P. et al. Papel da memória. Campinas (SP): Pontes, 1999. p. 49-57.

PÊCHEUX, M. A análise de discurso, três épocas. In: GADET, J.; HAK, T. (Org.). Por uma análise automática do discurso: uma introdução à obra de Michel Pêcheux. Campinas: Editora da UNICAMP, 1990.

PÊCHEUX, M.; FUCHS, C. A propósito da análise automática do discurso: atualização e perspectivas. In: GADET, J.; HAK, T. (Org.). Por uma análise automática do discurso: uma introdução à obra de Michel Pêcheux. Campinas: Editora da UNICAMP, 1990.

SANTOS, S. S. B. Pêcheux. In: OLIVEIRA, L. A. Estudos do discurso: perspectivas teóricas. São Paulo: Parábola, 2013.

SAUSSURE, F. Curso de Linguística Geral. 9. ed. São Paulo: Cultrix, 1979.

ZILBERBERG, C. Eléments de grammaire tensive. Limoges: Pulim, 2006.

ZILBERBERG, C. Louvando o acontecimento. Tradução de M. L. V. P. Diniz. Revista Galáxia, São Paulo, n. 13, p. 13-28, jun. 2007.

ZILBERBERG, C. Elementos de semiótica tensiva. Tradução de I. C. Lopes, L. Tatit e W. Beividas. São Paulo: Ateliê Editorial, 2011.

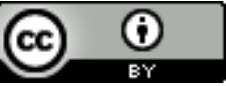

Este texto está licenciado com uma Licença Creative Commons Atribuição 4.0 Internacional. 